\title{
Prevalence of Acute Myocardial Infarction in Young Adults and Conventional Risk Factors
}

\author{
Dan $\mathrm{KK}^{1^{*}}$, Rahman $\mathrm{M}^{2}$, Saha $\mathrm{S}^{3}$, Das $\mathrm{J}^{4}$
}

${ }^{1}$ Kazal Kanti Dan, Assistant Professor, Department of Cardiology, Jashore Medical College, Jashore, Bangladesh

${ }^{2}$ Md Moshfequr Rahman, Junior Consultant (Cardiology), Adhunik Sadar Hospital, Narail, Bangladesh

${ }^{3}$ Sudipto Saha, Junior consultant (Cardiology), Shahid Shiekh Abu Naser Specialized Hospital, Khulna, Bangladesh

${ }^{4}$ Jharna Das, Associate Professor, Institute of Nuclear medicine and allied science, Bangladesh Atomic Energy Commission, Khulna Medical College Hospital Campus, Khulna, Bangladesh.

DOI:10.36347/sjams.2021.v09i01.032

| Received: 23.12.2020 | Accepted: 11.01.2021 | Published: 30.01 .2021

*Corresponding author: Kazal Kanti Dan

Abstract

Original Research Article

Introduction: Smoking, diabetes mellitus, hypertension, dyslipidemia, sedentary life style, and positive family history are known as conventional risk factors of coronary artery disease (CAD) and the prevalence of it varies across populations. There is paucity of data in our country about the prevalence of risk factors for acute myocardial infarction (AMI) in young adults $\leq 35$ year. Aim of the Study:This study aims to assess Prevalence of Acute Myocardial Infarction (AMI) in Young Adults with Conventional Risk Factors. Material \& Methods: It is an observational crosssectional single center study conducted in Jashore Medical College Hospital. A total of 1167 consecutive patients admitted with the diagnosis of Acute Myocardial Infarction (ST Elevation Myocardial Infarction: STEMI, and Non ST Elevation Myocardial Infarction: NSTEMI) were enrolled for the study from July 2019 to June 2020. Of these total patients 37 were in the age group of $\leq 35$ year. A proforma was designed to collect patient information which included age, gender, diabetes mellitus, dyslipidemia, hypertension, smoking, family history of coronary artery disease (CAD), level of physical activity, and Body Mass Index(BMI). Results: Of the total study population (1167) a significant number (37) i.e, $3.17 \%$ fall in younger adult's $\leq 35$ year. The conventional risk factors for AMI smoking, dyslipidemia and family history are major in both age groups but these risk factors are more prevalent in young adults ( $\leq 35$ year) in which smoking in male $25(67.57 \%$ ) vs female 0, dyslipidemia in male 34(91.89\%) vs female 2(5.41\%) and family history of MI in male 33(89.19\%) vs female 2(5.41\%). Conclusion: Present study showed high prevalence of Acute Myocardial Infarction in younger age group $\leq 35$ year. Conventional risk factors were present in both the age groups, but smoking, dyslipidemia and family history of CAD were significantly higher in younger age group.

Key words: Acute Myocardial Infarction, Diabetes, Dyslipidemia, Hypertension, Smoking.

Copyright $\odot 2021$ The Author(s): This is an open-access article distributed under the terms of the Creative Commons Attribution 4.0 International License (CC BY-NC 4.0) which permits unrestricted use, distribution, and reproduction in any medium for non-commercial use provided the original author and source are credited.

\section{INTRODUCTION}

Coronary artery disease (CAD) is a leading cause of morbidity and mortality in both developing and developed countries [1]. Epidemiological studies have established cigarette smoking [2], diabetes mellitus (DM) [3], hypertension (HTN) [4], dyslipidemia, family history, obesity, and sedentary life style [5] as independent risk factors for CAD and have been labeled as conventional risk factors [6]. Acute Myocardial Infarction includes Non-ST elevation myocardialinfarction (NSTEMI) and ST elevation myocardial infarction (STEMI) which needs urgent or emergency care to reduce mortality or morbidity. Reduction of these risk factors has been convincingly shown to reduce the risk of future events [2, 7].
Prevalence of these risk factors may vary across populations [8]. Our study aims to assess the prevalence of conventional risk factors in patients who were admitted with diagnosis of AMI particularly in younger age group in Jashore Medical College Hospital.

\section{OBJECTIVES}

a) General objective

- To assess prevalence of acute myocardial infarction in young adults

\section{b) Specific objectives}

- Identify the clinical profile of myocardial infarction and common risk factors. 


\section{Methodology and Materials}

It is an observational cross-sectional single center study conducted in Jashore Medical College Hospital. A total of 1167 patients admitted with the diagnosis of Acute Myocardial Infarction (NSTEMI, and STEMI) were enrolled for the study from July 2019 to June 2020. A proforma was designed to collect patient information which included age, gender, diabetes mellitus, dyslipidemia, hypertension, smoking, family history of Coronary artery disease, BMI, and levelof physical activity.

Definition of Acute Myocardial Infarction was adapted from the third universal definition of myocardial infarction (Eur Heart J 2012; 33:25512267) as a rise and or fall of cardiac troponin with at least one value above the 99th percentile of upper refference limit with at least one of the following:

- Ischemic symptoms

- Significant new or presumed new $\mathrm{ST}=\mathrm{T}$ change

- New onset LBBB

- Appearance of new pathological Q wave

- Echocardiographic evidence of new regional wall motion abnormality or viable myocardial loss.

Diabetes mellitus was defined as previously diagnosed cases or fasting plasma glucose of $\geq 6.1 \mathrm{mmol} / 1$ or $\geq 11.1 \mathrm{mmol} / 12$ hour after $75 \mathrm{~g}$ oral glucose after overnight fasting.

Hypertension was defined as the previously diagnosed cases or blood pressure of $>140 / 90 \mathrm{mmHg}$ on at least two occasions or in single sitting with evidence of end organ damage.

Dyslipidemia was defined as Total cholesterol (TC) $>200 \mathrm{mg} / \mathrm{dl}$ or Low density lipoprotein (LDL-C) $>130 \mathrm{mg} / \mathrm{dl}$ or Triglyceride (TG) $>150 \mathrm{mg} / \mathrm{dl}$ or High density lipoprotein $(\mathrm{HDL}=\mathrm{C})<40 \mathrm{mg} / \mathrm{dl}$ in male and $<45 \mathrm{mg} / \mathrm{dl}$ in female.

Obesity was defined as BMI $\geq 30 \mathrm{~kg} / \mathrm{m} 2$ and overweight as $(25-29.9) \mathrm{kg} / \mathrm{m} 2$. Positive family history was taken as diagnosis of CAD in first degree relatives in age less than 50 year in male and less than 55 year in female.

Statistical analysis: Continuous variables were expressed as mean with range and categorical variables as count with percentage. Groups were compared using Chi Square test (cross tabulation method) for categorical variables. $\mathrm{P}$ value less than 0.05 was considered statistically significant with
95\% confidence interval. Data were analyzed using the Statistical Package for the Social Sciences (SPSS) version 22.0.

\section{Results}

During the study period we identified 1167 patients with Acute Myocardial Infarction of which 37 patients were finally selected in young age group of $\leq 35$ year by excluding the patients where proper data of conventional risk factors were not available. Of the total study population (1167) a significant number (37) i.e, $3.17 \%$ fall in young adults $\leq 35$ year shown in Fig1.Table-1 shows of the total study population male were $1039(89.03 \%)$ and female were $128(10.97 \%)$ in gender distribution. In age >35year were $1130(96.83 \%)$ and $\leq$ 35year were $37(3.17 \%)$.Weight of participants below 60 $\mathrm{kg}$ were $669(57.33 \%)$ and more than $60 \mathrm{~kg}$ were $498(42.67 \%)$. Regarding residency rural were 939(80.46\%) and urban were 228(19.54\%). Education of the participants were with No education 128(10.97\%), Primary 527(45.16\%), Secondary $270(23.14 \%)$ and Graduation \& above 242(20.74\%). Of the total study population $1010(86.55 \%)$ had a family history of MI where $157(13.45 \%)$ had no family history of MI. The participants were further divided into two groups on the basis of their age as $\leq 35$ year and $>35$ year among which $96.83 \%$ were in $>35$ year and $3.17 \%$ were in $\leq 35$ year group. Mean value for total cholesterol (TC) was $201.03 \mathrm{mg} / \mathrm{dl}$, which ranged from $117 \mathrm{mg} / \mathrm{dl}$ to $319 \mathrm{mg} / \mathrm{dl}$. Mean value for low-density lipoprotein cholesterol (LDL-C) was $122.87 \mathrm{mg} / \mathrm{dl}$, which ranged from $71 \mathrm{mg} / \mathrm{dl}$ to $188 \mathrm{mg} / \mathrm{dl}$. Mean value for Triglyceride (TG) was $167.29 \mathrm{mg} / \mathrm{dl}$, which ranged from $79 \mathrm{mg} / \mathrm{dl}$ to $462 \mathrm{mg} / \mathrm{dl}$. Mean value for High-density lipoprotein-cholesterol (HDL-C) was $39.14 \mathrm{mg} / \mathrm{dl}$, which ranged from $19 \mathrm{mg} / \mathrm{dl}$ to $62 \mathrm{mg} / \mathrm{dl}$. The prevalence of CAD risk factors among the study population is summarized in Table-2. Hypertension was present in $540(46.27 \%)$ in the total study population where $479(41.05 \%)$ in male and $61(5.23 \%)$ in female and this was the most frequently observed risk factors in Acute Myocardial Infarction with $\mathrm{P}=0.888$, whereas prevalence of smoking was seen in $455(38.99 \%)$ where $396(33.93 \%)$ in male vs59(5.06\%) in female $(\mathrm{P}<0.05)$. Diabetes was present in $124(10.63 \%)$ in male vs33 (2.83\%) in female among 1167 study populations with $\mathrm{P}$ value of 0.077 . The prevalence of CAD risk factors among the study population by age is summarized in Table 3. Smoking is by far the most common observed risk factor in age $\leq 35$ year which was seen in male $17(1.46 \%)$ and 0 in female where in age $>35$ year group this was seen in male $422(36.16 \%)$ and in female $16(1.37 \%)$. Among 1167 study population hypertension was seen in male $12(1.03 \%)$ and in female $1(0.09 \%)$ in age $\leq 35$ year group and in age $>35$ year group this was seen in male $441(37.79 \%)$ and female in $86(7.37 \%)$. Diabetes was seen in male 5(0.43\%) and female in $1(0.09 \%)$ in age $\leq 35$ year group and in age $>35$ year group this was seen in male $127(10.88 \%)$ and female in $24(2.06 \%)$.The blood lipid analysis showed that the 
mean level of total cholesterol was $201.03 \mathrm{mg} / \mathrm{dl}$ (IQR 117-319mg/dl), LDL-C was $122.87 \mathrm{mg} / \mathrm{dl}$ (IQR, 71-188 $\mathrm{mg} / \mathrm{dl}$ ), HDL-C was $39.14 \mathrm{mg} / \mathrm{dl}$ (IQR, 19-62) and Triglyceride was $167.29 \mathrm{mg} / \mathrm{dl}$ (IQR, 79-462 mg/dl). From Table-4 TC, LDL-C and TG all three levels were lower in men than women and HDL-C was seen higher in men compared to women though the difference were non-significant $(\mathrm{p} \geq 0.05)$. As shown in Fig.-2 The conventional risk factors for ACS smoking, dyslipidemia and family history are major in both age groups but these risk factors are more prevalent in younger $(\leq 35$ year) in which smoking in male $25(67.57 \%)$ vs female 0 , dyslipidemia in male $34(91.89 \%)$ vs female $2(5.41 \%)$ and family history of $\mathrm{MI}$ in male $33(89.19 \%)$ vs female $2(5.41 \%)$.

Table-1: Demographic and study characteristics $(\mathrm{N}=1167)$

\begin{tabular}{|l|l|l|}
\hline Characteristic & N & $\%$ \\
\hline Gender & 1039 & 89.03 \\
\hline Male & 128 & 10.97 \\
\hline Female & 37 & 3.17 \\
\hline Age & 1130 & 96.83 \\
\hline$\leq 35$ year & \\
\hline$>35$ year & 669 & 57.33 \\
\hline Weight & 498 & 42.67 \\
\hline Below 60 kg & \\
\hline More than 60 kg & 228 & 19.54 \\
\hline Residency & 939 & 80.46 \\
\hline Urban & 128 & 10.97 \\
\hline Rural & 527 & 45.16 \\
\hline Education & 270 & 23.14 \\
\hline No education & 242 & 20.74 \\
\hline Primary & 1010 \\
\hline Secondary & 86.55 \\
\hline Graduation/Above & 157 & 13.45 \\
\hline Family History of MI & \\
\hline Yes & \\
\hline No &
\end{tabular}

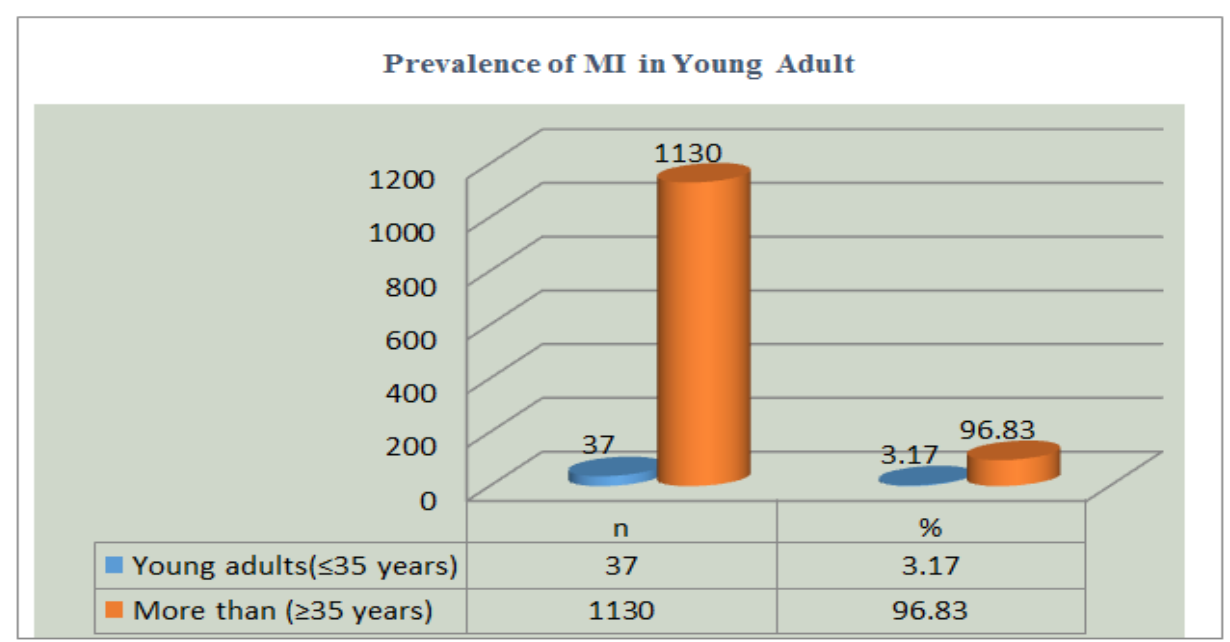

Fig-1: Prevalence of MI in Young Adult (N=1167)

Table-2: Prevalence of risk factors according to sex $(\mathrm{N}=1167)$

\begin{tabular}{|l|l|l|l|l|l|l|l|}
\hline \multirow{2}{*}{ Risk factors } & \multicolumn{2}{|l|}{ patients $\mathbf{( N = 1 1 6 7 )}$} & \multicolumn{2}{l|}{ Male(N=1039) } & \multicolumn{2}{l|}{ Female( N=128) } & \multirow{2}{*}{ P value } \\
\cline { 2 - 7 } & $\mathbf{N}$ & $\mathbf{\%}$ & $\mathbf{N}$ & $\mathbf{\%}$ & $\mathbf{N}$ & $\mathbf{\%}$ & \\
\hline Smoking & 455 & 38.99 & 396 & 33.93 & 59 & 5.06 & $<0.05$ \\
\hline Hypertension & 540 & 46.27 & 479 & 41.05 & 61 & 5.23 & 0.888 \\
\hline Diabetes & 157 & 13.45 & 124 & 10.63 & 33 & 2.83 & 0.077 \\
\hline Alcoholic & 15 & 1.29 & 15 & 1.29 & 0 & 0.00 & 0.077 \\
\hline Total & $\mathbf{1 1 6 7}$ & $\mathbf{1 0 0 . 0 0}$ & $\mathbf{1 0 1 4}$ & $\mathbf{8 6 . 8 9}$ & $\mathbf{1 5 3}$ & $\mathbf{1 3 . 1 1}$ & \\
\hline
\end{tabular}


Table-3: Prevalence of risk factors by age $(\mathrm{N}=1167)$

\begin{tabular}{|c|c|c|c|c|c|c|c|c|c|c|c|}
\hline \multirow{3}{*}{ Risk factors } & \multicolumn{2}{|c|}{ Patients (N=1167) } & \multicolumn{4}{|c|}{$\leq 35$ year $(N=37)$} & \multicolumn{4}{|c|}{$>35$ year $(\mathrm{N}=1130)$} & \multirow{3}{*}{$P$ value } \\
\hline & \multirow{2}{*}{$\mathbf{N}$} & \multirow{2}{*}{$\%$} & \multicolumn{2}{|c|}{ Male } & \multicolumn{2}{|c|}{ Female } & \multicolumn{2}{|c|}{ Male } & \multicolumn{2}{|c|}{ Female } & \\
\hline & & & $\mathbf{N}$ & $\%$ & $\mathbf{N}$ & $\%$ & $\mathbf{N}$ & $\%$ & $\mathbf{N}$ & $\%$ & \\
\hline Smoking & 455 & 38.99 & 17 & 1.46 & 0 & & 422 & 36.16 & 16 & 1.37 & $<0.05$ \\
\hline Hypertension & 540 & 46.27 & 12 & 1.03 & 1 & 0.09 & 441 & 37.79 & 86 & 7.37 & 0.888 \\
\hline Diabetes & 157 & 13.45 & 5 & 0.43 & 1 & 0.09 & 127 & 10.88 & 24 & 2.06 & 0.077 \\
\hline Alcoholic & 15 & 1.29 & 1 & 0.09 & 0 & & 14 & 1.2 & 0 & 0 & \\
\hline Total & 1167 & 100.00 & 35 & 3.01 & 2 & 0.18 & 1004 & 86.03 & 126 & 10.8 & \\
\hline
\end{tabular}

Table-4: Pattern of Lipid profiles in study populations by sex $(\mathrm{N}=1167)$

\begin{tabular}{|c|c|c|c|c|c|c|c|}
\hline \multirow{2}{*}{ Lipid Profiles } & \multicolumn{2}{|c|}{ Patients $(\mathrm{N}=1167)$} & \multicolumn{2}{|c|}{ Male(N=1039) } & \multicolumn{2}{|c|}{ Female( $N=128)$} & \multirow{2}{*}{$P$ value } \\
\hline & $\mathbf{N}$ & $\%$ & $\mathbf{N}$ & $\%$ & $\mathbf{N}$ & $\%$ & \\
\hline TC (IQR)(mg/dl) & \multicolumn{2}{|c|}{ 201.03(117-319) } & \multicolumn{2}{|c|}{$199.90(117-319)$} & \multicolumn{2}{|c|}{$203.29(118-302)$} & \multirow{3}{*}{0.77} \\
\hline TC>200 mg/dl(\%) & 498 & 42.67 & 421 & 36.08 & 77 & 6.60 & \\
\hline $\mathrm{TC} \leq 200 \mathrm{mg} / \mathrm{dl}(\%)$ & 669 & 57.33 & 618 & 52.96 & 51 & 4.37 & \\
\hline LDL-C (IQR)(mg/dl) & \multicolumn{2}{|c|}{ 122.87(71-188) } & \multicolumn{2}{|c|}{$120.74(44-188)$} & \multicolumn{2}{|c|}{$127.15(47-259)$} & \multirow{3}{*}{0.77} \\
\hline LDL-C>130 mg/dl(\%) & 470 & 40.27 & 415 & 35.56 & 55 & 4.71 & \\
\hline LDL-C $\leq 130 \mathrm{mg} / \mathrm{dl}(\%)$ & 697 & 59.73 & 624 & 53.47 & 73 & 6.26 & \\
\hline HDL-C (IQR)(mg/dl) & \multicolumn{2}{|c|}{39.14 (19-62) } & \multicolumn{2}{|c|}{ 39.97(19-53) } & \multicolumn{2}{|c|}{ 37.47(20-62) } & \multirow{3}{*}{0.67} \\
\hline HDL-C $\geq 40 \mathrm{mg} / \mathrm{dl}(\%)$ & 526 & 45.07 & 458 & 39.24593 & 68 & 5.83 & \\
\hline HDL-C <40 mg/dl(\%) & 641 & 54.93 & 581 & 49.78578 & 60 & 5.14 & \\
\hline TG (IQR)(mg/dl) & \multicolumn{2}{|c|}{$167.29(79-462)$} & \multicolumn{2}{|c|}{ 166.19(79-340) } & \multicolumn{2}{|c|}{$169.50(84-462)$} & \multirow{3}{*}{0.48} \\
\hline $\mathrm{TG}>150 \mathrm{mg} / \mathrm{dl}(\%)$ & 725 & 62.13 & 646 & 55.36 & 79 & 6.77 & \\
\hline $\mathrm{TG} \leq 150 \mathrm{mg} / \mathrm{dl}(\%)$ & 442 & 37.87 & 393 & 33.68 & 49 & 4.20 & \\
\hline
\end{tabular}

Table-5: Distribution of dyslipidemia by sex $(\mathrm{N}=1167)$

\begin{tabular}{|l|l|l|l|l|l|l|l|}
\hline \multirow{2}{*}{ Subject } & \multicolumn{2}{|l|}{ patients $(\mathbf{N}=1167)$} & \multicolumn{2}{l|}{ Male(N=1039) } & \multicolumn{2}{l|}{ Female( $\mathbf{N}=128)$} & \multirow{2}{*}{ P value } \\
\cline { 2 - 7 } & $\mathbf{N}$ & $\mathbf{\%}$ & $\mathbf{N}$ & $\mathbf{\%}$ & $\mathbf{N}$ & $\mathbf{\%}$ & \\
\hline No dyslipidemia & 256 & 21.94 & 227 & 21.85 & 29 & 2.49 & \multirow{2}{*}{0.63} \\
\hline Dyslipidemia & 911 & 78.06 & 812 & 67.18 & 99 & 8.48 & \\
\hline Total & 1167 & 100 & 1039 & 89.03 & 9 & 10.97 & \\
\hline
\end{tabular}

Table-6: Distribution of dyslipidemia by Age $(\mathrm{N}=1167)$

\begin{tabular}{|c|c|c|c|c|c|c|c|c|c|c|c|}
\hline \multirow{3}{*}{ Subject } & \multicolumn{2}{|c|}{ Patients (N=1167) } & \multicolumn{4}{|c|}{$\leq 35$ year $(\mathrm{N}=37)$} & \multicolumn{4}{|c|}{$>35$ year $(\mathrm{N}=1130)$} & \multirow{3}{*}{$P$ value } \\
\hline & \multirow{2}{*}{$\mathbf{N}$} & \multirow{2}{*}{$\%$} & \multicolumn{2}{|c|}{ Male } & \multicolumn{2}{|c|}{ Female } & \multicolumn{2}{|c|}{ Male } & \multicolumn{2}{|c|}{ Female } & \\
\hline & & & $\mathbf{N}$ & $\%$ & $\mathbf{N}$ & $\%$ & $\mathbf{N}$ & $\%$ & $\mathbf{N}$ & $\%$ & \\
\hline No dyslipidemia & 256 & 21.94 & 1 & 0.09 & 0 & 0 & 160 & 13.71 & 95 & 8.14 & \multirow{2}{*}{0.63} \\
\hline Dyslipidemia & 911 & 78.06 & 34 & 2.91 & 2 & 0.17 & 590 & 50.56 & 287 & 24.42 & \\
\hline Total & 1167 & 100 & 35 & 3 & 2 & 0.17 & 750 & 64.27 & 380 & 32.56 & \\
\hline
\end{tabular}

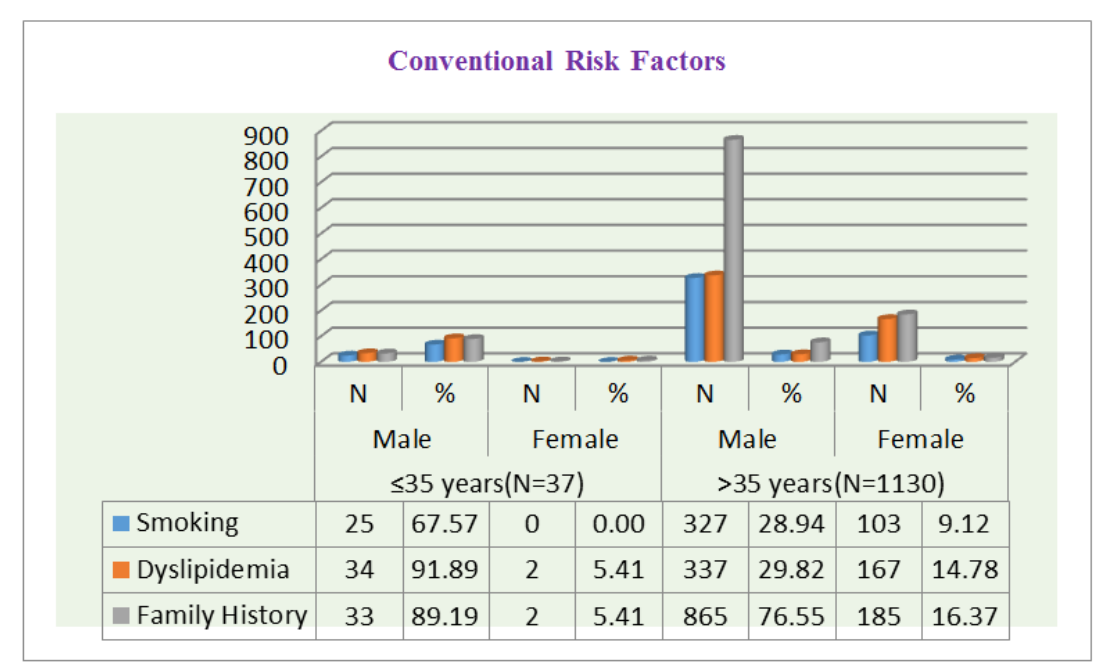

Fig-2: Distribution of Conventional Risk Factors ( $\mathrm{N}=1137)$ 


\section{DISCUSSION}

In the current study the total population was divided into two groups: $\leq 35$ year and $>35$ year. Younger patients (age $\leq 35$ year) with AMI event were $3.17 \%$. Kalimuddinet al. [9] in a study showed $3 \%$ of AMI in the age group of $\leq 20$ year. Fournier JA et al.[10]. Showed AMI in $4.1 \%$ in patient's age $\leq 40$ year. It is a matter of concern that younger patients' percentage is increasing for acute coronary syndrome(ACS). The study done by Adhikariet al. [11] revealed clear preponderance of smoking, hypertension and dyslipidemia as common risk actors in acute STElevation myocardial inarction as in our current study. The incidence of acute coronary syndrome (ACS) is lower in women than men in all age groups [12], which is consistent with our study. The finding that ACS event is more common in male patients in our study is consistent with report from many studies around the globe Observational Global Registry of Acute Coronary Events (GRACE) [13]. We found high prevalence of Dyslipidemia (78.06\%), Hypertension (46.27\%), Smoking (38.99\%), and Diabetes $(13.45 \%)$ in our study population. The study conducted by Adhikariet al. [11] have lower prevalence of dyslipidemia, $45.5 \%$ compared to our 78.06 which is much higher, it is probably due to our inclusion of raised TG in the definition of dyslipidemia[14]. Cigarette smoking plays a critical role in the development of CAD. Smoking is considered one of the most important modifiable risk factors for increasing cardiovascular disease. In our study, the prevalence of current smoking was $33.93 \%$ in male and $5.06 \%$ in female. Smoking was significantly higher in male population in overall, but more common in younger age group in our study. These results are similar to other recent studies. It was the second most frequently encountered conventional risk factor with acute STEMI living in Turkish study population [15]. Diabetes mellitus (DM) is a major health challenge in many Asian populations. However its prevalence is somewhat lower than that observed in developed countries [16], it is significant among South Asians, having $2 \%$ prevalence in rural South Asia but approaching $20 \%$ prevalence in urban South Asia and amongst immigrant South Asians [17-19]. In our study it is $3^{\text {rd }}$ common among the conventional risk factors only after Hypertension and Smoking. Prevalence of DM in INTERHEART study was $26 \%$ in women, $16 \%$ in men [8]. The diabetes is a powerful risk factor in women. The higher prevalence of diabetes in women than in men is not consistent with our study (Male10.63\% vsFemale2.83\%). This could due to higher prevalence of AMI in young male and deprivation of hospitalization of the female counterpart. Hypertension is one of the main factors leading to atherogenesis and the development of vulnerable plaques whose instability or rupture is responsible for the development of acute coronary syndrome (ACS). In general population, the prevalence of hypertension rises progressively with age in both male and female. In GUSTO -1 trial which enrolled 41021 STEMI patients prevalence of a history of previous hypertension was $38.1 \%$ (15544 of 41021) [20]. Similarly, In GISSI-2 with 20491STEMI patients, history of HTN was present in about $35 \%$ of the whole population [21]. In epidemiological studies performed in N-STEMI patients, chronic HTN is the most prevalent risk factors [22]. Similar to these studies prevalence of HTN inpatient presented with ACS at our center was $46.27 \%$. From all the registries and the data available up to now [20, 21, 23-25], ACS patients with hypertension are more likely to be male and older age similar to that of our study with HTN in male being $41.05 \%$ and $5.23 \%$ in female. An observational study has shown untreated dyslipidemia as a strong predictor of in-hospital mortality [26]. Clinically significant changes in lipid occur after an ACS event [27]. From the time of admission to next morning TC and LDL-C level can undergo a change of $7 \%$ and $10 \%$ respectively, in patients with MI and 5\% and 6\% in those with unstable angina [31]. Our study showed $73.5 \%$ had at least one alteration in lipid levels. On other hand this may hint underestimation of the true prevalence of dyslipidemia as risk factors for Nepalese population. In previous observational study [28], every $1 \mathrm{mg} / \mathrm{dl}$ increment in HDL-C was reported to be associated with $2 \%-3 \%$ decrease risk of CVD in adult. In our study $54.93 \%$ of population has HDL-C $<40 \mathrm{mg} / \mathrm{dl}$, which co-relates that HDL-C level is one of the conventional important risk factors for ACS. Elevated levels of TG are an independent risk factor for CHD [29]. Our study demonstrated $\mathrm{TG}$ level $>150 \mathrm{mg} / \mathrm{dl}$ as $62.13 \%$. A reduction of $1 \%$ in $\mathrm{TC}$ level has been shown to reduce the risk for coronary artery disease [30] assuming that the reverse is true, our study does not correlate with previous studies as in our study $57.33 \%$ of population have TC level $<200 \mathrm{mg} / \mathrm{dl}$, and suffered acute coronary syndrome event. LDL-C $>130 \mathrm{mg} / \mathrm{dl}$ is seen in smaller percentage of $40.27 \%$ compared to $59.73 \%$ of LDL-C $\leq 130 \mathrm{mg} / \mathrm{dl}$. This may point out that even lower level of LDL-C can be a risk factor for ACS even [31, 32] and future study needs to validate more accurate event. Our study clearly shows that conventional risk factors occur in most of the ACS patients in cluster. Adhikari CM et al. [11] showed that $70 \%$ population had more than 2 risk factors which is same in our study too. All the above data from studies show that most of the ACS patients have cluster of conventional risk factors and primary prevention against all of the four conventional cardiovascular risk factors should be addressed by education, diet, exercise and pharmacologically.

\section{Limitations of THe Study}

This study has some limitations, such as its observational design and small sample size. Doses of statin taken by patient vary and many are not documented and Lipid profile was taken at variable time within 24 hours. Nonconventional risk factors were not evaluated in this study. 


\section{Conclusion and Recommendations}

Present study showed high prevalence of Acute Myocardial Infarction in younger age group with conventional risk factors especially smoking, dyslipidemia and positive family history for coronary artery disease suggesting the need for aggressive risk factor reduction in this age group as well as in general population.

\section{REFERENCES}

1. Lopez AD, Murray CC, The global burden of disease. 1998; 1990-2020, Nat Med. 4(11):1241-3.

2. Samet JM. The 1990 report of the surgeon general: the health benefits of smoking cessation. The American review of respiratory disease. 1990 Nov;142(5):993.

3. Stamler J, Vaccaro O, Neaton JD, Wentworth D, Multiple Risk Factor Intervention Trial Research Group. Diabetes, other risk factors, and 12-yr cardiovascular mortality for men screened in the Multiple Risk Factor Intervention Trial. Diabetes care. 1993 Feb 1;16(2):434-44.

4. MacMahon S, Peto R, Collins R, Godwin J, Cutler J, Sorlie P, Abbott R, Neaton J, Dyer A, Stamler J. Blood pressure, stroke, and coronary heart disease: part 1, prolonged differences in blood pressure: prospective observational studies corrected for the regression dilution bias. The Lancet. 1990 Mar 31;335(8692):765-74.

5. VERSHCUREN W, Jacobs DR, KARVONEN M, NEDELJKOVIC S, NISSINEN A. Serum total cholesterol and long-term coronary heart disease mortality in different cultures: twenty-five: year follow-up of the seven countries study. JAMA, the journal of the American Medical Association. 1995;274(2):131-6.

6. Khot UN, Khot MB, Bajzer CT, Sapp SK, Ohman EM, Brener SJ, Ellis SG, Lincoff AM, Topol EJ. Prevalence of conventional risk factors in patients with coronary heart disease. Jama. 2003 Aug 20;290(7):898-904.

7. Collins R, Peto R, MacMahon S, Godwin J, Qizilbash N, Hebert P, Eberlein KA, Taylor JO, Hennekens $\mathrm{CH}$, Fiebach NH. Blood pressure, stroke, and coronary heart disease: part 2, shortterm reductions in blood pressure: overview of randomised drug trials in their epidemiological context. The Lancet. 1990 Apr 7;335(8693):82738.

8. Yusuf $\mathrm{S}$, Hawken $\mathrm{S}$, Ôunpuu $\mathrm{S}$, Dans $\mathrm{T}$, Avezum A, Lanas F, McQueen M, Budaj A, Pais P, Varigos J, Lisheng L. Effect of potentially modifiable risk factors associated with myocardial infarction in 52 countries (the INTERHEART study): case-control study. The lancet. 2004 Sep 11;364(9438):937-52.

9. Kalimuddin $\mathrm{M}$, Ahmed N, Badiuzzzaman $\mathrm{M}$, Ahmed MN, Dutta A, Banik D, Kabiruzzaman M, Rahman H, Huq TS, Jamal MF. AMI in very young (aged $\leq 35$ years) Bangladeshi patients: Risk factors
\& coronary angiographic profile. Clinical Trials and Regulatory Science in Cardiology. 2016 Jan $1 ; 13: 1-5$.

10. Fournier JA, Sanchez A, Quero J, Fernandez- Cortacero JA, González- Barrero A. Myocardial infarction in men aged 40 years or less: A prospective clinical- angiographic study. Clinical cardiology. 1996 Aug;19(8):631-6.

11. Adhikari CM, Prajapati D, Baniya B, Regmi S, Bogati A, Thapaliya S. Prevalence of Conventional Risk Factors in ST Segment Elevation Myocardial Infarction Patients in ShahidGangalal National Heart Centre, Nepal. JNMA J Nepal Med Assoc. 2014 Jul 1;52(195):914-.

12. Andreotti F, Rio T, Gianmarinaro M, Navarese EP, Marchese N, CreaF,Pathophysiology of ischemic heart disease inwomen, G ItalCardiol (Rome).2012;13(6): 396-400.

13. Carruthers KF, Dabbous OH, Flather MD, Starkey I, Jacob A, Macleod D, Fox KA. Contemporary management of acute coronary syndromes: does the practice match the evidence? The global registry of acute coronary events (GRACE). Heart. 2005 Mar 1;91(3):290-8.

14. González-Pacheco H, Vargas-Barrón J, Vallejo M, Piña-Reyna Y, Altamirano-Castillo A, SánchezTapia P, Martínez-Sánchez C. Prevalence of conventional risk factors and lipid profiles in patients with acute coronary syndrome and significant coronary disease. Therapeutics and clinical risk management. 2014;10:815.

15. Sonmez K, Akcay A, Akcakoyun M, Demir D, Elonu OH, Pala S, Duran NE, Gencbay M, Degertekin M, Turan F. Distribution of risk factors and prophylactic drug usage in Turkish patients with angiographically established coronary artery disease. Journal of cardiovascular risk. 2002 Aug;9(4):199-205.

16. King H. Aubert Re, Herman WH. Global burden of diabetes 1995-2025. Prevalence, numerical estimates and projections, Diabetes Care. 1998;21(9):1414

17. Anand SS, Yusuf S, Vuksan V, Devanesen S, Teo KK, Montague PA, Kelemen L, Yi C, Lonn E, Gerstein H, Hegele RA. Differences in risk factors, atherosclerosis, and cardiovascular disease between ethnic groups in Canada: the Study of Health Assessment and Risk in Ethnic groups (SHARE). The lancet. 2000 Jul 22;356(9226):279-84.

18. Riste L, Khan F, Cruickshank K. High prevalence of type 2 diabetes in all ethnic groups, including Europeans, in a British inner city: relative poverty, history, inactivity, or 21st century Europe? Diabetes care. 2001 Aug 1;24(8):1377-83.

19. Venkataraman R, Nanda NC, Baweja G, Parikh N, Bhatia V. Prevalence of diabetes mellitus and related conditions in Asian Indians living in the United States. The American journal of cardiology. 2004 Oct 1;94(7):977-80. 
20. An international randomized trial comparing four thrombolytic strategies for acute myocardial infarction. NEngl J Med. 1993;329(10): 673-82.

21. Fresco C, Avanzini F, Bosi S, Franzosi MG, Maggioni AP, Santoro L, Bellanti G. Prognostic value of a history of hypertension in 11,483 patients with acute myocardial infarction treated with thrombolysis. GISSI-2 Investigators. GruppoItaliano per lo Studio della, Sopravvivenanell'InfartoMiocardico. Journal of hypertension. 1996 Jun;14(6):743-50.

22. Hasdai D, Behar S, Wallentin L, Danchin N, Gitt AK, Boersma E, Fioretti PM, Simoons ML, Battler A. A prospective survey of the characteristics, treatments and outcomes of patients with acute coronary syndromes in Europe and the Mediterranean basin. The Euro Heart Survey of Acute Coronary Syndromes (Euro Heart Survey ACS). European heart journal. 2002 Aug 1;23(15):1190-201.

23. Burt VL, Whelton P, Roccella EJ, Brown C, Cutler JA, Higgins M, Horan MJ, Labarthe D. Prevalence of hypertension in the US adult population: results from the Third National Health and Nutrition Examination Survey, 1988-1991. Hypertension. 1995 Mar;25(3):305-13.

24. Wolf-Maier K, Cooper RS, Banegas JR, Giampaoli S, Hense HW, Joffres M, Kastarinen M, Poulter N, Primatesta P, Rodríguez-Artalejo F, Stegmayr B. Hypertension prevalence and blood pressure levels in 6 European countries, Canada, and the United States. Jama. 2003 May 14;289(18):2363-9.

25. Ali WM, Zubaid M, El-Menyar A, Mahmeed WA, Al-Lawati J, Singh R, Ridha M, Al-Hamdan R,
Alhabib K, Suwaidi JA. The prevalence and outcome of hypertension in patients with acute coronary syndrome in six Middle-Eastern countries. Blood pressure. 2011 Feb 1;20(1):20-6.

26. Montalescot G, Dallongeville J, Van Belle E, Rouanet S, Baulac C, Degrandsart A. STEMI and NSTEMI: are they so different? 1 year outcomes in acute myocardial infarction as defined by the ESC/ACC definition (the OPERA registry), Eur Heart J. 2007; 28: 1409-17.

27. Rosenson RS, Myocardial injury: the acute phase response and lipoprotein metabolism, J Am CollCardiol. 1993; 22(3): 933-40.

28. Maron DJ, The epidemiology of low levels of highdensity lipoprotein cholesterol in patients with and without coronary artery disease, Am J Cardiol. 2000; 86(12a): 11-41.

29. Austin MA, Hokanson JE, Edwards KL, Hypertriglyceridemia as a cardiovascularrisk factor, Am J Cardiol.81:4A (1998)7B-12B.

30. Consensus conference, lowering blood cholesterol to prevent heart disease, JAMA. 1985; 253(14): 2080-6.

31. Kostev K, Parhofer KG, Dippel FW, Prevalence of high-risk cardiovascular patients with therapyresistant hypercholesterolemia, CardiovascEndocrinol.2017; 6(2): 81-5.

32. O'Brien EC, Simon DN, Roe MT, Wang TY, Peterson ED, Alexander KP, Statin Treatment by Low-Density Lipoprotein Cholesterol Levels in Patients With Non-ST-Segment Elevation Myocardial Infarction/Unstable Angina Pectoris (from theCRUSADE Registry), Am J Cardiol. 115. 